JOURNAL OF

SYNCHROTRON

RADIATION

ISSN 1600-5775

Received 25 September 2020

Accepted 13 November 2020

Edited by G. Grübel, HASYLAB at DESY, Germany

Keywords: X-ray free-electron laser; intensity correlation; X-ray fluorescence

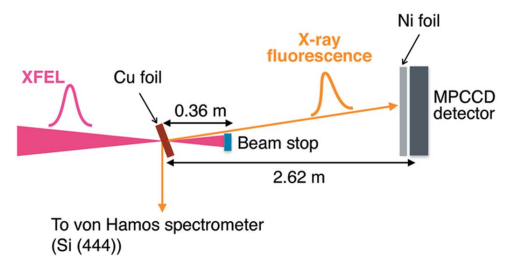

C 2021 International Union of Crystallography

\section{Determination of $X$-ray pulse duration via intensity correlation measurement of $X$-ray fluorescence. Erratum}

\author{
Ichiro Inoue, ${ }^{a *}$ Kenji Tamasaku, ${ }^{a}$ Taito Osaka, ${ }^{a}$ Yuichi Inubushi ${ }^{a, b}$ and \\ Makina Yabashi ${ }^{\mathrm{a}, \mathrm{b}}$
}

${ }^{\mathbf{a}}$ RIKEN SPring-8 Center, 1-1-1, Kouto, Sayo, Hyogo 679-5148, Japan, and ${ }^{\mathbf{b}}$ Japan Synchrotron Radiation Research Institute, 1-1-1 Kouto, Sayo, Hyogo 679-5198, Japan. *Correspondence e-mail: inoue@spring8.or.jp

Corrections to equations and experimental results in the paper by Inoue et al. [(2019). J. Synchrotron Rad. 26, 2050-2054] are made.

The correct versions of equations (2) and (3) in the paper by Inoue et al. (2019) are as follows:

$$
\begin{gathered}
g_{f}^{(2)}\left(r_{1}, r_{2}\right)=1+\frac{1}{2}\left|j\left(r_{1}, r_{2}\right)\right|^{2} \int \Pi(\tau)|\gamma(\tau)|^{2} \mathrm{~d} \tau, \\
g_{f}^{(2)}\left(r_{1}, r_{2}\right)=1+\frac{1}{2} g_{0}^{(2)} \exp \left(-\frac{\Delta x^{2}}{2 l_{x}^{2}}\right) \exp \left(-\frac{\Delta y^{2}}{2 l_{y}^{2}}\right) .
\end{gathered}
$$

The additional factors of $1 / 2$ on the right-hand sides of these equations represent a decrease in intensity correlation of $\mathrm{X}$-ray fluorescence due to the unpolarized nature of the fluorescence (Trost et al., 2020; Goodman, 2007).

Accordingly, the degree of intensity correlation $\left[g_{0}^{(2)}\right]$ and the XFEL duration $\left[2 \sqrt{2 \ln 2} \sigma_{t}\right]$ evaluated by the experiment also need to be corrected; the values of $g_{0}^{(2)}$ and $2 \sqrt{2 \ln 2} \sigma_{t}$ shown in Section 4 should be $0.0262 \pm 0.008$ and $5.1 \pm 0.2 \mathrm{fs}$, respectively. The determined XFEL duration is consistent with previous estimations by other methods (Inubushi et al., 2017; Inoue et al., 2018), in which the XFEL duration was evaluated to be less than $10 \mathrm{fs}$. Although the determined XFEL duration is shorter than the electron bunch duration measured by a radiofrequency deflector ( $\sim 10 \mathrm{fs}$ in FWHM), such discrepancy could be explained by insufficient time resolution of the deflector ( $\sim 10 \mathrm{fs})$ (Ego et al., 2015).

\section{Acknowledgements}

We thank the authors of Trost et al. (2020) for pointing out the errors in the original paper.

\section{References}

Ego, H., Maesaka, H., Sakurai, T., Otake, Y., Hashirano, T. \& Miura, S. (2015). Nucl. Instrum. Methods Phys. Res. A, 795, 381-388.

Goodman, J. W. (2007). Speckle Phenomena in Optics: Theory and Applications. Englewood: Roberts and Co.

Inoue, I., Hara, T., Inubushi, Y., Tono, K., Inagaki, T., Katayama, T., Amemiya, Y., Tanaka, H. \& Yabashi, M. (2018). Phys. Rev. Accel. Beams, 21, 080704.

Inoue, I., Tamasaku, K., Osaka, T., Inubushi, Y. \& Yabashi, M. (2019). J. Synchrotron Rad. 26, 2050-2054.

Inubushi, Y., Inoue, I., Kim, J., Nishihara, A., Matsuyama, S., Yumoto, H., Koyama, T., Tono, K., Ohashi, H., Yamauchi, K. \& Yabashi, M. (2017). Appl. Sci. 7, 584.

Trost, F., Ayyer, K. \& Chapman, H. (2020). New J. Phys. 22, 083070. 